\title{
Bicuspid aortic valve with aortic aneurysms
}

\author{
Tirone E. David, MD
}

\author{
From the Division of Cardiovascular Surgery of Toronto General Hospital and Peter Munk Cardiac Centre, \\ Toronto, Ontario, Canada. \\ Disclosures: Author has nothing to disclose with regard to commercial support. \\ Received for publication Oct 30, 2017; accepted for publication Nov 9, 2017; available ahead of print Dec 14, \\ 2017. \\ Address for reprints: Tirone E. David, MD, 200 Elizabeth St, 4N453, Toronto, Ontario M5G 2C4, Canada (E-mail: \\ tirone.david@uhn.ca). \\ J Thorac Cardiovasc Surg 2018;156:467-8 \\ $0022-5223 / \$ 36.00$ \\ Copyright (c) 2017 by The American Association for Thoracic Surgery \\ https://doi.org/10.1016/j.jtcvs.2017.11.010
}

\begin{abstract}
"In rare cases, rupture and dissection occur in aneurysms of my current size $(4.6 \mathrm{~cm})$. To me, the danger of rupture or dissection is scariest of all. I'm not required to wait until my aneurysm reaches the surgical standard of 5.5 centimeters to get on the operating table, and I don't intend to. I'm doing it at 5."
\end{abstract}

$$
\text { The Wall Street Journal-April 22, } 2003^{1}
$$

The fear of aortic rupture or dissection expressed by the Wall Street Journal writer is common among patients diagnosed with aneurysms, ${ }^{1}$ and they need reassurance that under proper medical surveillance, the probability of a serious adverse event is indeed rare. The "AATS Consensus Guidelines on Bicuspid Aortic Valve-Related Aortopathy" published in this issue of the Journal ${ }^{2}$ summarize important aspects on the management of patients with bicuspid aortic valve (BAV) with associated dilatation of the proximal thoracic aorta, and they are very useful to practicing physicians who look after these patients. These guidelines present a more conservative approach in the management of this syndrome compared with previous guidelines. For those interested in the current knowledge of BAV-related aortopathy, the online version is an important reading. It shows that we still have a lot to learn about the biological behavior of BAV.

BAV-associated aortopathy may affect any portion of the proximal thoracic aorta from the aortic root to the aortic arch. We have operated on numerous patients with BAV during the past 3 decades and have never seen a case of arch aneurysm that extended beyond the innominate artery. A few of our patients also had aneurysm of the innominate artery. The most common site of aneurysm was the ascending aorta, followed by ascending aorta and aortic root (which often involved more the posterior than the anterior aortic sinus), and lastly, isolated aortic root (which often involved both sinuses with cephalad displacement of the coronary arteries).

Our decision to replace any or all proximal aortic segments have been consistent with these new American

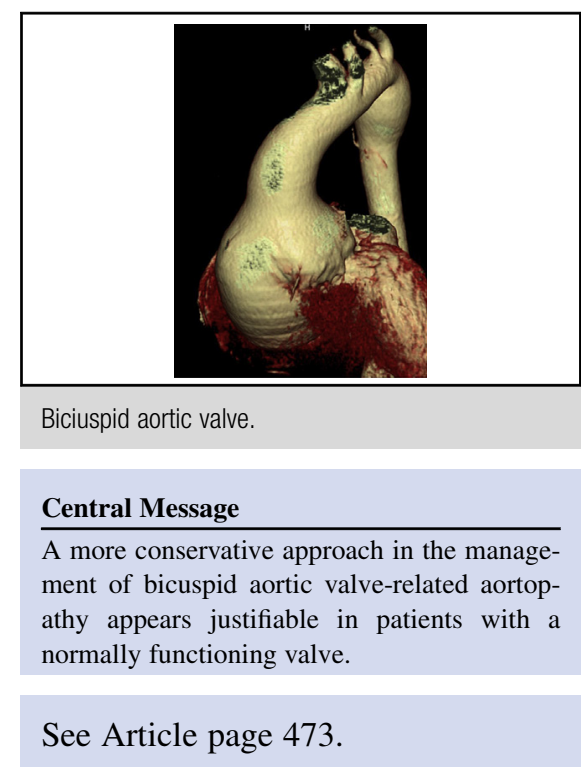

Association for Thoracic Surgery guidelines. ${ }^{2}$ We have been more aggressive with isolated aortic root aneurysm with normally functioning BAV, in which case we recommend surgery when the root reaches $50 \mathrm{~mm}$, particularly if we believe that an aortic valve-sparing operation is feasible. We have used a diameter of $55 \mathrm{~mm}$ to recommend surgery for ascending aorta or arch aneurysm with normally functioning BAV. Replacement of the ascending aorta in these patients is not as simple as one may think because correction of the diameter of the sinotubular junction in these patients may induce cusp prolapse and aortic insufficiency. ${ }^{3,4}$ The free margins of the cusps often have to be shortened during supracoronary replacement of the aorta in patients with ascending aortic aneurysm $\geq 55 \mathrm{~mm}$ and normally functioning BAV. ${ }^{3,4}$ As correctly stated in these new guidelines, these patients should be operated on by aortic surgeons with experience in the reconstruction of BAV. $^{2}$

Most patients with BAV require surgery for aortic stenosis or insufficiency rather than for the associated aortopathy. ${ }^{5}$ The decision to replace any or all proximal aortic segments at the time of aortic valve surgery varies with the degree of dilatation and elongation of the ascending aorta, the thickness of the arterial wall, the patient's age, and type of valve implanted. The diameter of the ascending aorta has been the principal determinant of replacement, and for more than a decade we have used the cut-off of $45 \mathrm{~mm} .{ }^{6}$ However, we have left alone $45-\mathrm{mm}$ aortas in octogenarian patients in whom the aortotomy could be closed safely after aortic valve replacement, but we have replaced 
paper-thin aortas of $40 \mathrm{~mm}$. We tend to be more aggressive and resect all segments when a mechanical aortic valve is implanted, particularly in younger patients. Having said that, one must be sure that a composite replacement of the aortic valve and ascending aorta is associated with similar operative risk as an isolated aortic valve replacement, something that only experienced aortic surgeons can do. The same can be said about replacement of the proximal aortic arch.

In our practice, the mean age of patients who undergo surgery for aortic valve dysfunction due to BAV is 65 years of age, and most patients chose to have a bioprosthetic valve. Thus, in some cases of ascending aorta of 40 to $45 \mathrm{~mm}$, we have simply performed an aortoplasty along its greater curvature to reduce its diameter to approximately $30 \mathrm{~mm}{ }^{7}$ This maneuver has also been useful during the Ross procedure in young patients. ${ }^{8}$ In patients with combined ascending aortic and aortic root aneurysm in whom the dilatation of the root is largely in the posterior aortic sinuses, we have replaced the ascending and the posterior aortic sinus by tailoring a tubular Dacron graft to recreate the aortic sinus and leave the coronary arteries attached to the anterior aortic sinus when a bioprosthetic valve is implanted. A formal root replacement is done when a mechanical aortic valve is used or both aortic sinuses are aneurysmal.
Finally, patients with aortic root aneurysms associated with genetic syndromes may have BAV, and surgery is recommended with smaller aortic roots depending on the type of syndrome.

\section{References}

1. Helliker K. A time bomb near my heart. Wall Street Journal. April 22, 2003.

2. Borger MA, Fedak PWM, Stephens EH, Gleason TG, Girdauskas E, Ikonomidis J, et al. AATS consensus guidelines on bicuspid aortic valve-related aortopathyExecutive Summary. J Thorac Cardiovasc Surg. 2018;156:473-80.

3. David TE, Feindel CM, Armstrong S, Maganti M. Replacement of the ascending aorta with reduction of the diameter of the sinotubular junction to treat aortic insufficiency in patients with ascending aortic aneurysm. J Thorac Cardiovasc Surg. 2007:133:414-8.

4. Asano M, Kunihara T, Aicher D, El Beyrouti H, Rodionycheva S, Schäfers HJ. Mid-term results after sinutubular junction remodelling with aortic cusp repair. Eur J Cardiothorac Surg. 2012;42:1010-5.

5. Michelena HI, Prakash SK, Della Corte A, Bissel MM, Anavekar N, Mathieu M, et al. Bicuspid aortic valve: identifying knowledge gaps and rising to the challenge from the International Bicuspid Aortic Valve Consortium (BAVCon). Circulation. 2014;129:2691-704.

6. Borger MA, Preston M, Ivanov J, Fedak PW, Davierwala P, Armstrong S, et al. Should the ascending aorta be replaced more frequently in patients with bicuspid aortic valve disease? J Thorac Cardiovasc Surg. 2004;128:677-83.

7. Bauer M, Pasic M, Schaffarzyk R, Siniawski H, Knollmann F, Meyer R, et al. Reduction aortoplasty for dilatation of the ascending aorta in patients with bicuspid aortic valve. Ann Thorac Surg. 2002;73:720-3.

8. Conaglen P, Luthra S, Skillington P. Comparison of reduction ascending aortoplasty and ascending aortic replacement for bicuspid valve related aortopathy in young adult patients undergoing aortic valve replacement-long-term followup. Heart Lung Circ. 2009;18:337-42. 